\title{
PENGEMBANGAN MEDIA AUDIO VISUAL PANDUAN PRAKTIS POLA HIDUP SEHAT BAGI LANSIA
}

\author{
Lutfi Wibawa, Hiryanto \& Eko Budi Prasetyo \\ FIP, Universitas Negeri Yogyakarta \\ email: luthfiuny@gmail.com
}

\begin{abstract}
Abstrak: Pengembangan Media Audio Visual Panduan Praktis Pola Hidup
Sehat bagi Lansia. Penelitian ini menghasilan media audio visual berupa compact disc (CD) panduan praktis pola hidup sehat bagi lansia dan modul kuliah pada jenjang S1 jurusan Pendidikan Luar Sekolah pada matakuliah Pendidikan Orang Dewasa. Penelitian pengembangan ini dilaksanakan di Daerah Istimewa Yogyakarta dengan sasaran kelompok-kelompok lanjut usia yang tergabung dalam paguyuban lansia. Dalam penelitian ini, data dikumpulkan dengan menggunakan metode forum group discussion, wawancara mendalam, dokumentasi dan observasi. Data yang terkumpul dianalisis menggunakan teknik analisis kualitatif. Penelitian dan pengembangan ini dilakukan dalam dua tahun, tahun pertama telah menghasilkan CD panduan praktis pola hidup sehat bagi lansia yang sudah tervalidasi secara terbatas dan modul kuliah pada jenjang S1 jurusan Pendidikan Luar Sekolah pada matakuliah Pendidikan Orang Dewasa.
\end{abstract}

Kata Kunci: CD, Kesehatan Lansia, Pengembangan Media

\begin{abstract}
Development of Audio Visual Media Practical Guide for the Elderly Healthy Lifestyle. This research resulted in a audio-visual media such as compact discs (CDs) practical guide healthy lifestyle for the elderly and lecture modules on S1 majoring in School Education in Adult Education courses. The development research conducted in Yogyakarta with the target groups of elderly who are members of the elderly community. In this study, data were collected by using group forum discution, in-depth interviews, documentation and observation. Data were analyzed using qualitative analysis techniques. Research and development is carried out in two years, the first year has produced a practical guide CD healthy lifestyles for seniors who already validated in a limited and lecture modules on S1 Department of School Education in Adult Education courses.
\end{abstract}

Keywords: CD, Development Media, Seniors' Health

\section{PENDAHULUAN}

Provinsi dengan usia harapan hidup yang lebih tinggi teridentifikasi mempunyai jumlah penduduk lanjut usia yang lebih banyak. Suatu wilayah disebut berstruktur tua jika persentase lanjut usianya lebih dari 7 persen. Dari seluruh provinsi di Indonesia, ada 11 provinsi yang penduduk lansianya sudah lebih dari 7 persen, yaitu Daerah
Istimewa Yogyakarta, Jawa Timur, Jawa Tengah, Bali, Sulawesi Selatan, Sumatera Barat, Sulawesi Utara, Nusa Tenggara Barat, Jawa Barat dan Nusa Tenggara Timur. Sedangkan lima provinsi dengan persentase lansia terendah adalah: Papua (2,15 persen); Papua Barat (2,92 persen), Kepulauan Riau (3,78 persen), Kalimantan Timur (4,53 persen), dan Riau (4,86 persen) (BPS, 2007). 
Badan kesehatan dunia WHO bahwa penduduk lansia di Indonesia pada tahun 2020 mendatang sudah mencapai angka $11,34 \%$ atau tercatat 28,8 juta orang, balitanya tinggal $6,9 \%$ yang menyebabkan jumlah penduduk lansia terbesar di dunia (Anonim, 2008). Dari sisi kualitas hidup, selain pendidikan, penduduk lanjut usia juga mengalami masalah kesehatan. Data menunjukkan bahwa ada kecenderungan angka kesakitan lanjut usia mengalami peningkatan dari tahun ke tahun. Kondisi ini tentunya harus mendapatkan perhatian berbagai pihak. Lanjut usia yang sakit-sakitan akan menjadi beban bagi keluarga, masyarakat dan bahkan pemerintah, sehingga akan menjadi beban dalam pembangunan. Oleh sebab itu, kita harus menjadikan masa lanjut usia menjadi tetap sehat, produktif dan mandiri.

Harapan hidup penduduk di Daearah Istimewa Yogyakarta semakin meningkat pada tahun 2011, BPS menyatakan bahwa usia harapan hidup masyarakat Yogyakarta sampai pada usia 71 tahun. Faktor yang mempengaruhi adalah meningkatnya kondisi sosial ekonomi, pelayanan kesehatan dan perbaikan kondisi kesehatan. Secara biologis proses penuaan adalah menurunnya daya tahan fisik, yaitu semakin rentan terhadap serangan berbagai penyakit yang mengarah kepada kematian.

Pada penduduk usia lanjut beberapa hal yang menjadi tanggungjawab perkembangan adalah menyesuaikan diri dengan menurunnya kekuatan fisik atau kesehatan secarabertahap, menyesuaikan diri dengan masa kemunduran atau pensiun dan berkurangnya pendapatan serta menyesuaikan diri atas kematian pasangan hidup. Tugas lainnya adalah menjadi anggota kelompok sebaya, mengikuti pertemuan-pertemuan sosial dan kewajiban-kewajiban sebagai war- ga Negara, membentuk pengaturan kehidupan yang memuaskan serta menyesuaikan diri dengan peran sosial secara fleksibel.

Meski kemampuan fisik menurun, sebagian besar lanjut usia sehat dan aktif yang berusaha untuk memenuhi kepuasan hidup. Kepuasan hidup bagi penduduk lanjut usia adalah semangat berpartisipasi dalam berbagai wilayah kehidupan, suka mengerjakan sesuatu secara antusias, resolusi dan keteguhan, keselarasan antar keinginan dan tujuan yang dicapai, konsep diri positif, berfikir tentang dirinya sebagai seseorang yang berharga, suasana hati menunjukkan kebahagiaan, optimis, senang dengan hidupnya.

Penduduk usia lanjut dikatakan berhasil bila memenuhi beberapa kriteria di antaranya:(1) fungsi jantung, kemampuan kognitif, kesehatan mental yang tercermin dari kondisi akhir usia lanjut, (2). Produktivitas, kondisi ekonomi, kondisi kesehatan, (3) Panjang umur sebagai tanda kesehatan fisik dan mental seseorang. Dengan harapan hidup penduduk yang semakin meningkat berarti pula jumlah penduduk lanjut usia semakin banyak. Dengan banyaknya penduduk usia lanjut memerlukan pendampingan agar penduduk lanjut usia tersebut berhasil melewati masa tuanya.

Terkait dengan hal tersebut di atas, ada tiga masalah penting yang menjadi fokus penelitian ini, yaitu: Satu, bagaimanakah kebutuhan kesehatan lanjut usia sehingga mampu melewati kehidupan dimasa tua dengan berhasil. Dua, bagaimanakah pengembangan model panduan praktis hidup sehat bagai lanjut usia yang mampu memenuhi tuntutan kehidupan lanjut usia. Tiga, bagaimanakah pengembangan compact disc (CD) panduan praktis pola hidup sehat bagi lanjut usia, yang mampu 
memberikan panduan kepada lanjut usia dalam meraih keberhasilan hidup di masa usia tua.

\section{METODE}

Penelitian pengembangan media audio visual panduan praktis pola hidup sehat bagi lanjut usia di Daerah Istimewa Yogyakarta ini menggunakan pendekatan research and development. Penelitian ini dirancang dengan pendekatan penelitian pengembangan (Research and Development) dari Borg and Gall seperti yang dikemukakan oleh Sukmadinata, 2009). Adapun model pengembangan yang digunakan adalah model prosedural yaitu model penelitian pengembangan yang bersifat deskriptif dengan mengikuti langkah-langkah untuk menghasilkan suatu produk. Borg and Gall mengemukakan sepuluh langkah alur pengembangan, dalam penelitian pengembangan yaitu: (1) Melakukan penelitian pendahuluan, dengan kegiatan pengukuran kebutuhan, studi literatur, dan penelitian awal. (2) Merencanakan perencanaan, meliputi menyusun rencana penelitian yang terdiri dari kemampuan yang diperlukan dalam pelaksanaan penelitian, merumuskan tujuan, menentukan desain, dan pengujian dalam lingkup terbatas. (3) Menciptakan produk awal, yang berupa model awal atau model tentatif. (4) Melakukan uji coba awal dalam kelompok kecil. (5) Melakukan revisi hasil uji coba awal untuk menghasilkan draf model I. (6) Melakukan uji coba dilapangan yang lebih besar (lapangan utama). (7) Melakukan revisi dari hasil uji coba lapangan utama. (8) Melaksanakan uji pelaksanaan lapangan terhadap pengguna. (9) Revisi produk/model akhir. (10) Melakukan desiminasi dan implementasi produk/ model. Dalam pandangan Sukmadinata (2006), penelitian dan pengembangan adalah suatu proses atau langkah-langkah untuk mengembangkan suatu produk atau penyempurnaan produk yang telah ada, yang dapat dipertanggungjawabkan.

Produk yang dihasilkan dalam penelitian ini adalah CD panduan praktis hidup sehat yang tervalidasi secara luas dan terdesiminasikan ke kelompok sasaran, artikel yang siap dimasukkan dalam jurnal ilmiah, modul kuliah pada matakuliah pendidikan orang dewasa. Setelah ditemukan persoalan kesehatan pada lansia yang memerlukan panduan praktis agar para lansia mampu mengatasi persoalan tersebut, peneliti berusaha melakukan tahapan-tahapan kegiatan pada tahun pertama sebagai berikut: Satu, pengumpulan data (analisis masalah dan potensi). Kedua, kegiatan penyusunan data teoritik di lakukan dengan mengkaji dan mengumpulkan bahan kajian tentang lansia. Ketiga, penyusunan draf awal panduan pola hidup sehat lansia. Empat, kegiatan pengembangan CD pembelajaran yang materinya di ambil dari draf panduan pola hidup lansia yang telah tersusun. Lima, validasi ahli materi dan ahli media.

\section{HASIL DAN PEMBAHASAN}

Uraian berikut mencakup kebutuhan pembelajaran pola hidup lansia sebagai bahan awal merancang $C D$ panduan praktis hidup sehat lanjut usia yang di peroleh melalui kegiatan pengumpulan data dengan menggunakan Focus Group Discussion (FGD) dari dua lokasi penelitian yakni di paguyuban lansia di Kalurahan Iromejan Kota Yogyakarta dan Desa Girimulyo, Kab Kulonprogo.

\section{Kebiasaan yang Kurang Mendukung Kesehatan Lanjut Usia}

Perilaku seorang lanjut usia akan senantiasa memberikan pengaruh bagi kondisi kesehatannya. Jika seseorang 
mampu meninggalkan kebiasaan dan prilaku yang buruk maka akan memberikan kontribusi yang positif bagi kesehatannya. Beberapa temuan dari kebiasaan yang kurang mendukung bagi kesehatan lansia seperti yang sudah di kemukan pada bagian sebelumnya, yaitu: pola tidur yang kurang teratur dan pola makan kurang teratur dan kurang minum. Kebiasaan ini tentunya akan membuat kondisi fisik si lansia akan mengalami atau menemu permasalahanpermasalahanan tertentu seperti cepat lelah, mudah terserang penyakit, letih, lesu, kurang gairah, malas beraktifitas dan lain sebagainya.

Kebiasaan burung ini jika berlangsung dalam jangka waktu lama dampaknya adalah kesehatan lansia yang terganggu dan terancam sehingga lanjut usia tidak mungkin melewati masa tuanya dengan bahagia. Secara teoritis dan kajian kesehatan sebenarnya ada beberapa bentuk perilaku buruk yang sering muncul pada lanjut usia yang harus ditinggalkan, kebiasaan-kebiasaan itu antara lain sebagai berikut: (1) Kurang berserah diri, (2) Pemarah, merasa tidak puas, murung, dan putus asa. (3) Sering menyendiri.Kurang melakukan aktivitas fisik/olahraga/kurang gerak. (4) Makan tidak teratur dan kurang minum. (5) Kebiasaan merokok dan meminum minuman keras. (6) Minum obat penenang dan penghilang rasa sakit tanpa aturan. (7) Melakukan kegiatan yang melebihi kemampuan. (8) Menganggap kehidupan seks tidak diperlukan lagi. (9) Tidak memeriksakan kesehatan secara teratur. Secara rinci tampilan data hasil penelitian tentang kebiasaan buruk lansia dapat dibaca pada Tabel 1.

Tabel 1. Tampilan Perilaku Buruk Lanjut Usia

\begin{tabular}{|c|c|c|}
\hline \multicolumn{2}{|c|}{ Kebiasaan buruk lansia } & \multirow{2}{*}{ Materi Pembelajaran } \\
\hline Temuan Penelitian & Teoritis & \\
\hline \multirow{12}{*}{$\begin{array}{l}\text { 1. Pola tidur yang } \\
\text { kurang teratur } \\
\text { 2. Pola makan } \\
\text { kurang teratur dan } \\
\text { kurang minum }\end{array}$} & 1. Kurang berserah diri & 1. Kurang berserah diri \\
\hline & 2. Pemarah, merasa tidak puas, & 2. Pemarah, merasa tidak puas, \\
\hline & murung, dan putus asa & murung \\
\hline & 3. Sering menyendiri & 3. Sering menyendiri \\
\hline & $\begin{array}{l}\text { 4. Kurang melakukan aktivitas } \\
\text { fisik/olahraga/kurang gerak }\end{array}$ & $\begin{array}{l}\text { 4. Kurang melakukan aktivitas } \\
\text { fisik/olahraga/kurang gerak }\end{array}$ \\
\hline & $\begin{array}{l}\text { 5. Makan tidak teratur dan } \\
\text { kurang minum }\end{array}$ & $\begin{array}{l}\text { 5. Makan tidak teratur dan } \\
\text { kurang minum }\end{array}$ \\
\hline & $\begin{array}{l}\text { 6. Kebiasaan merokok dan } \\
\text { meminum minuman keras }\end{array}$ & $\begin{array}{l}\text { 6. Kebiasaan merokok dan } \\
\text { meminum minuman keras }\end{array}$ \\
\hline & $\begin{array}{l}\text { 7. Minum obat penenang dan } \\
\text { penghilang rasa sakit tanpa } \\
\text { aturan }\end{array}$ & $\begin{array}{l}\text { 7. Minum obat penenang dan } \\
\text { penghilang rasa sakit tanpa } \\
\text { aturan }\end{array}$ \\
\hline & $\begin{array}{l}\text { 8. Melakukan kegiatan yang } \\
\text { melebihi kemampuan }\end{array}$ & $\begin{array}{l}\text { 8. Melakukan kegiatan yang } \\
\text { melebihi kemampuan }\end{array}$ \\
\hline & $\begin{array}{l}\text { 9. Menganggap kehidupan seks } \\
\text { tidak diperlukan lagi }\end{array}$ & $\begin{array}{l}\text { 9. Menganggap kehidupan } \\
\text { seks tidak diperlukan lagi }\end{array}$ \\
\hline & 10. Tidak memeriksakan & 10. Tidak memeriksakan \\
\hline & kesehatan secara teratur & kesehatan secara teratur \\
\hline
\end{tabular}


Tabel 1 memberikan gambaran perbandingan antara temuan lapangan dan kajian teori terkait kebiasaan yang kurang baik atau buruk yang dilakukan para lanjut usia. Sehingga memunculkan bahan dan tema-tema gereratif yang bisa dikembangkan dan di angkat menjadi materi pembelajaran tenteng perilaku buruk yang harus di hindari oleh para lanjut usia.

\section{Perilaku yang Mendukung Kesehatan Lanjut Usia}

Kondisi kesehatan lanjut usia baik lahir maupun batin akan sangat dipengaruhi oleh kebiasaan dan prilaku yang dilewati dalam kesehariannya. Orang lanjut usia yang perilakunya positif akan memberikan dampak yang positif pula pada kondisi kesehatannya. Sebagai prasarat seorang lanjut usia mampu melewati kehidupan dengan bahagia dan sejahtera lahir dan batin tentunya dengan senantiasa menjaga kebiasaan dan prilaku yang positif.

Dari kajian lapangan dapat di sampaikan bahwa beberapa temuan perilaku positif lanjut usia diantaranya adalah sebagai berikut: menjalin hubungan yang baik dengan keluarga dan sesama, melakukan olahraga ringan, mau menerima keadaan sebagai lanjut usia, mendekatkan diri kepada Tuhan Yang Maha Kuasa. Dengan perilaku yang cenderung positif ini memberikan dorongan dan energi bagi lanjut usia melewati kehidupan dengan penuh gairah dan sengat yang masih kuat.

Gairah hidup tentunya memberikan dampak bagi semangat melanjutkan kehidupan dan mempersiapkan kehidupan setelah di dunia ini. Lanjut usia memerlukan sentuhan-sentuhan lembut yang berupa energi positif tersebut yang mampu memunculkan motivasi dari dalam diri, sehingga segala tindakan muncul atas dorongan dan motivasi dari dalam diri, tidak lagi tergantung pada sesuatu yang berada di luar kediriannya.

Untuk mendapatkan seorang lanjut usia yang mempunyai sikap dan perilaku semacam ini tentunya memelukan perhatian kusus. Sehingga yang menjadi fokus utama adalah memunculkan kesadaran penuh dari dalam diri lanjut usia untuk senantiasa berperilaku yang positif, dengan harapan mampu mendukung pola kehidupan yang bahagia.

Secara teoritis perilaku positif atau ke-biasaan baik yang mampu memberi dampak positif bagi kondisi kesehatan lanjut usia adalah dapat di sebutkan sebagai berikut: (1) Mendekatkan diri pada Tuhan Yang Maha Kuasa. (2) Mau menerima keadaan, sabar dan optimis serta meningkatkan rasa percaya diri dengan melakukan kegiatan yang sesuai dengan kemampuan. (3) Menjalin hubungan yang baik dengan keluarga dan sesama. (4) Melakukan olahraga ringan setiap hari. (5) Makan sedikit tapi sering dan pilih makanan yang sesuai serta banyak minum. (6) Berhenti merokok dan minum minuman keras. (7) Minumlah obat sesuai anjuran dokter/petugas kesehatan. (8) Mengembangkan hobi sesuai kemampuan. (9) Tetap bergairah dan memelihara kehidupan seks. (10) Memeriksakan kesehatan dan gigi secara teratur.

Beberapa bentuk perilaku dan aktivitas seperti diatas memerlukan pembiasaan dan latihan-latihan kusus sehingga tidak lagi menjadi aktifitas sebagai beban tetapi sebagai aktifitas yang menyenangkan. Tentunya banyak sekali manfaat yang dapat diambil dari kebiasaan positif diatas, beberapa manfaat uatam itu antara lain: (1) Lebih taqwa dan tenang dalam menjalani kehidupan. (2) Menghadirkan keceriaan dengan mengisi waktu luang. (3) Keberadaannya tetap 
diakui oleh keluarga dan masyarakat. (4) Kesegaran dan kebugaran tubuh tetap terpelihara. (5) Terhindar dari kegemukan/kekurusan dan penyakitpenyakit yang berbahaya dimasa tua. (6) Mencegah keracunan obat dan efek samping lainnya. (7) Penyakit jantung, paru-paru dan kanker dapat dicegah. (8) Mengurangi stress dan kecemasan. (9) Hubungan harmonis tetap terpelihara. (10) Gangguan kesehatan dapat diketahui dan diatasi sejak dini.

Serangkaian manfaat yang bisa diperoleh dari kebiasaan berperilaku positif bagi lanjut usia ini, tidak semata-mata menjadi tujuan utama akan tetapi menjadi jembatan agar para lanjut usia mampu menemukan dirinya dlam kehidupan yang tenang, nyaman, tenteram, bahagia lahir dan batin sehingga mampu mempersiapkan kehidupan akhirat. Secara sederhana dari uraian yang telah disampaiakan diatas, berikut akan di sajikan dalam bentuk tabel uraian tentang perilaku positif lanjut usia yang berpotensi memberikan kehidupan yang bahagia, tabel itu dapat dibaca pada Tabel 2.

Tabel 2. Perilaku Positif Lanjut Usia yang Mendukung Kesehatan

\begin{tabular}{|c|c|c|}
\hline \multicolumn{3}{|c|}{ Perilaku Positif Lansia } \\
\hline Temuan Penelitian & Teoritis & Manfaat \\
\hline $\begin{array}{l}\text { - Mendekatkan diri } \\
\text { kepada Tuhan } \\
\text { Yang Maha } \\
\text { Kuasa. } \\
\text { - Menjalin } \\
\text { hubungan yang } \\
\text { baik dengan } \\
\text { keluarga dan } \\
\text { sesama } \\
\text { Melakukan } \\
\text { olahraga ringan, } \\
\text { mau menerima } \\
\text { keadaan sebagai } \\
\text { lanjut usia }\end{array}$ & $\begin{array}{l}\text { - Mendekatkan diri pada } \\
\text { Tuhan Yang Maha Kuasa } \\
\text { Mau menerima keadaan, } \\
\text { sabar dan optimis serta } \\
\text { meningkatkan rasa percaya } \\
\text { diri dengan melakukan } \\
\text { kegiatan yang sesuai dengan } \\
\text { kemampuan } \\
\text { - Menjalin hubungan yang } \\
\text { baik dengan keluarga dan } \\
\text { sesama } \\
\text { Melakukan olahraga ringan } \\
\text { setiap hari } \\
\text { Makan sedikit tapi sering } \\
\text { dan pilih makanan yang } \\
\text { sesuai serta banyak minum } \\
\text { Berhenti merokok dan } \\
\text { minum minuman keras } \\
\text { Minumlah obat sesuai } \\
\text { anjuran dokter/petugas } \\
\text { kesehatan } \\
\text { Mengembangkan hobi sesuai } \\
\text { kemampuan } \\
\text { Tetap bergairah dan } \\
\text { memelihara kehidupan seks } \\
\text { Memeriksakan kesehatan } \\
\text { dan gigi secara teratur. }\end{array}$ & $\begin{array}{l}\text { - Lebih taqwa dan tenang dalam } \\
\text { menjalani kehidupan } \\
\text { - Menghadirkan keceriaan } \\
\text { dengan mengisi waktu luang } \\
\text { - Keberadaannya tetap diakui } \\
\text { oleh keluarga dan masyarakat } \\
\text { - Kesegaran dan kebugaran } \\
\text { tubuh tetap terpelihara } \\
\text { - Terhindar dari kegemukan/ } \\
\text { kekurusan dan penyakit- } \\
\text { penyakit yang berbahaya } \\
\text { dimasa tua } \\
\text { - Mencegah keracunan obat } \\
\text { danefek samping lainnya } \\
\text { - Penyakit jantung, paru-paru } \\
\text { dan kanker dapat dicegah } \\
\text { Mengurangi stress dan } \\
\text { kecemasan } \\
\text { Hubungan harmonis tetap } \\
\text { terpelihara } \\
\text { Gangguan kesehatan dapat } \\
\text { diketahui dan diatasi sejak } \\
\text { dini. }\end{array}$ \\
\hline
\end{tabular}


Tabel 2 memberikan gambaran yang riil tentang kondisi lanjut usia di Kota Yogyakarta dan Kulonprogo yang ternyata masih memerlukan penyadaran pemahaman tentang perilaku positif yang lain yang masih banyak harus dipahami oleh mereka. Dengan Tabel 2 memungkinkan peneliti merumuskan tema-tema geratif dan pokok-pokok bahsan untuk menentukan materi pembelajaran untuk kesehatan lanjut usia.

\section{Pengembangan CD Pembelajaran}

Pengembangan CD pembelajaran panduan praktis pola hidup sehat bagi lanjut usia, dikembangkan dengan mengambil pokok-pokok materi dari data hasil penelitian dan kajian teoritis. CD pembelajaran ini merupakan media yang dapat di gunakan oleh para fasilitator dalam melakukan proses pembelajaran dengan lanjut usia dan keluarga. CD pembelajaran ini memuat hal-hal sebagai berikut: Satu, Pokok-pokok perilaku positif bagi lanjut usia, antara lain: (1) Mendekatkan diri pada Tuhan Yang Maha Kuasa. (2) Mau menerima keadaan, sabar dan optimis serta meningkatkan rasa percaya diri dengan melakukan kegiatan yang sesuai dengan kemampuan. (3) Menjalin hubungan yang baik dengan keluarga dan sesama. (4) Melakukan olahraga ringan setiap hari. (5) Makan sedikit tapi sering dan pilih makanan yang sesuai serta banyak minum. (6) Berhenti merokok dan minum minuman keras. (7) Minumlah obat sesuai anjuran dokter/ petugas kesehatan. (8) Mengembangkan hobi sesuai kemampuan. (9) Tetap bergairah dan memelihara kehidupan seks. 10) Memeriksakan kesehatan dan gigi secara teratur. Dua, Perilaku buruk yang sering muncul pada lanjut usia yang harus di tinggalkan, antara lain: (1) Kurang berserah diri. (2) Pemarah, merasa tidak puas, murung, dan putus asa. (3) Sering menyendiri. (4) Kurang melakukan aktivitas fisik/olahraga/ kurang gerak. (5) Makan tidak teratur dan kurang minum. (6) Kebiasaan merokok dan meminum minuman keras. (7) Minum obat penenang dan penghilang rasa sakit tanpa aturan. (8) Melakukan kegiatan yang melebihi kemampuan. (9) Menganggap kehidupan seks tidak diperlukan lagi. (10) Tidak memeriksakan kesehatan secara teratur.

\section{SIMPULAN}

Berdasarkan hasil analisis data dan pembahasan penelitian, dapat dirumuskan simpulan sebagai berikut: (1) Perilaku lanjut usia yang kurang mendukung untuk kesehatan adalah pola tidur yang kurang teratur dan pola makan kurang teratur serta kurang minum. (2) Perilaku lanjut usia yang mendukung untuk kesehatan adalah menjalin hubungan yang baik dengan keluarga dan sesama, melakukan olahraga ringan, mau menerima keadaan sebagai lanjut usia, mendekatkan diri kepada Tuhan Yang Maha Kuasa. (3) Pokok-pokok materi yang menjadi bahan untuk di kembangkan menjadi bahan ajar mata kuliah pendidikan orang dewasa dan CD pembelajaran pola hidup sehat bagi lanjut usia adalah : panduan perilaku positif dan perilaku negatif bagi lanjut usia, manfaat pola hidup sehat, upaya penjegahan penyakit dan peningkatan kesehatan bagi lanjut usia, peran keluarga terhadap lanjut usia, peran keluarga dalam menyajikan makanan bagi lanjut usia. (4) Penelitian ini juga telah menghasilkan draf awal materi pembelajaran pola hidup sehat bagi lanjut usia, CD pembelajaran yang belum tervalidasi, serta artikel ilmiah yang siap dimasukkan dalam jurnal ilmian terakreditasi nasional. 
Berdasarkan hasil penelitian tentang pengembangan media Audio Visual Panduan praktis Pola Hidup Sehat bagi Lansia, peneliti memberikan saran-saran sebagai berikut: (1) Bagi penduduk usia lanjut perlu mengupayakan untuk mengurangi pola-pola hidup yang kurang mendukung kesehatan seperti kurang tidur dan pola makan yang tidak baik. (2) Perilaku-perilaku yang dapat mendukung untuk kesehatan, seperti menjalin hubungan dengan sesame, anggota keluarga, melakukan aktivitas fisik seperti jalan-jalan, berkebun, bersihbersih rumah, mau menerima keadaan sebagaimana adanya, serta selalu mendekatkan diri kepada Tuhan Maha Esa dengan menjalankan kewajibannya sebagai umat beragama perlu selalu ditingkatkan.

\section{DAFTAR PUSTAKA}

Anonim, 2008. Jumlah Penduduk Lansia Diprediksi Melonjak. http://www. republika.co.id. Diunduh tanggal 12 Maret 2014.

BPS. 2007. Survei Sosial Ekonomi Nasional 2007. Jakarta.

Sukmadinata, N.S. (2009). Metodologi Penelitian Pendidikan. Bandung: Remaja Rosdakarya. 